\title{
Ciclo de CONFERENCIAS "Filosofía APLiCAdA EN EL PENSAMIENTO ESPAÑOL MODERNO Y CONTEMPORÁNEO”
}

\author{
GRUPO DE INVESTIGACIÓN "FILOSOFÍA APLICADA: \\ SUJETO, SUFRIMIENTO Y SOCIEDAD" \\ Universidad de Sevilla ${ }^{1}$ \\ haser@us.es
}

RECIBIDO: 12 DE NOVIEMBRE DE 2009

ACEPTADO: 1 DE MAYO DE 2010

\section{Introducción: ¿Filosofía Aplicada y pensamiento español?}

Filosofía Aplicada y pensamiento hispánico deberían haber encontrado trabazón desde los orígenes de la primera.

La Filosofía Aplicada supone un estudio reflexivo donde no se privilegia el "sobre" la vida, sino el "desde" la vida. Así, la Filosofía Aplicada supone una reflexión desde las cuitas personales de consultantes que acuden al filósofo no para hablar sobre la vida, sino siendo incapaces de evitar que ésta invada la consulta. La preocupación de despacho sobre el sentido existencial es acuciante cuando un consultante ha perdido recientemente a la mujer con la que convivió veinte años, el interés argumental sobre el amor de un ensayo filosófico aumenta su densidad desde las palabras de la adolescente que siente que le han roto el corazón $\mathrm{y}$, con ello, percibe que no tiene fuerzas ni argumentos para seguir adelante.

El pensamiento español se ha destilado en moldes sistemáticos, sin embargo, son más propicios a él los moldes literarios. Razón de ello son las guías, las novelas filosóficas o la filosofía literaria. La lectura de Baltasar Gracián, Calderón de la Barca, Unamuno o los dos Zambrano dan cumplida cuenta de ello. Además, el modo de hacer filosofía en contextos españoles es muy acorde a la labor desarrollada por el filósofo aplicado. Una de las acepciones de la filosofía de acervo común es la que

\footnotetext{
${ }^{1}$ Este artículo ha sido editado previamente en el libro Barrientos Rastrojo, J.(ed.): Filosofía Aplicada y circunstancia española, DOSS-CESHVAQ, Sevilla-Morelia, 2009.
} 
aconseja "tomarse la vida con filosofía". Esto no es sinónimo de desarrollar una existencia complicada en complejos sistemas abstractos, sino saber mantener entereza en adversidad, grandeza de ánimo en la consternación, agudeza en las problemáticas complejas, aceptación en las insolubles y paciencia (paz y ciencia) en todas ellas. La idea responde a un tratamiento de la vida tildada por un término que procede de uno de nuestros pensadores universales: hay que ser un Séneca en la vida.

Si la Filosofía Aplicada acarreaba el anhelo de un modo de hacer filosofía y el pensamiento español daba el marco para la respuesta, sólo quedaba establecer el nexo de unión. El ciclo de conferencias que abrimos en la Universidad de Sevilla ${ }^{2}$ pretendía comenzar este enlace tan escaso como necesario. Nos ocupamos de inaugurarlo en el curso 20082009 y esperamos poner continuarlo en sucesivas ediciones. A continuación, resumimos algunos de los puntos destacados de cada una de sus conferencias.

\section{Escepticismo, prudencia y arte de elegir: Baltasar Gracián y la Filosofía Aplicada}

El profesor José Ordóñez García, intensamente comprometido con el ámbito de la Filosofía Aplicada dentro y fuera de la universidad, comenzó su reflexión exponiendo su sorpresa por el enorme interés que Baltasar Gracián estaba despertando en la empresa y la ciudadanía estadounidense y anglosajona: ¿cómo es posible que un mundo tan pragmatista como el norteamericano, indicaba el ponente, se interese por un clásico del pensamiento español? Inmediatamente llegaba una posible respuesta: la lectura del Oráculo Manual se puede entender como un catálogo de conductas correctas y, por ende, una obra análoga a las obras de autoayuda tan extendidas en aquellos contextos geográficos.

\footnotetext{
2 El Seminario Internacional Universitario "Filosofía Aplicada a la Persona y a Grupos" fue financiado por el Vicerrectorado de Relaciones Institucionales y Extensión Universitaria y organizado por la Asociación Internacional Universitaria para la Filosofía Aplicada POIESIS. Puede consultarse más información en la blog del mismo: http://filosofia-aplicada.blogspot.com, último acceso 18 de diciembre de 2008.
} 
Sin embargo, Gracián es mucho más. Ordóñez cifra su interés para la Filosofía Aplicada en tres puntos: su escepticismo, la idea de prudencia y el arte de elegir.

Es llamativo que en un jesuita que nació con el siglo XVII se aferre a una primera idea escéptica, algo opuesto a la reflexión religiosa del medio y el momento histórico de Gracián. Esto, lejos de restarle valor, aumenta su interés para el filósofo, moscardón criticista por excelencia. El escepticismo fragua las bases para una máxima Graciána: nadie aprende sino a partir de la propia experiencia. Idea nodal que quiebra la el uso angloparlante que se le da a su obra en los últimos tiempos. Además, impulsa al lector de Gracián a plantearse una segunda cuestión: ¿cómo actuar si la experiencia del otro sirve de poco a mi propio aprendizaje? La idea de prudencia dará el marco formal de la respuesta.

Inicialmente, Gracián se aferra a un pensamiento pesimista y una concepción específica de la prudencia:

(1) El mundo no es como debería ser y nunca (o difícilmente) llegará a serlo.

(2) El sujeto prudente es aquel que, artificialmente, no se amolda a lo que es sino que intenta construir artificialmente algo que lo transforme.

De la primera aseveración, se produce una postura determinada: el mundo es el enemigo. Esta reflexión concierta con ciertas filosofías (platonismo) y ciertas concepciones de la fe (catolicismo del Siglo de Oro español).

De la segunda aseveración, se infiere la primera paradoja Graciána. La prudencia se corresponde con un deber específico. Ese deber ser se distancia de lo que el sujeto "naturalmente" es. Ahora bien, ¿realmente será posible conseguirlo una vez leída la primera aseveración? Si ser prudente es un "deber ser" y ese deber ser sólo con mucha dificultad se plasmará en el mundo, ¿cómo conseguirlo? Obviamente, la vía de la prudencia se sitúa en un "impasse". La propuesta de la lectura de Ordóñez es que habría que ser imprudentes.

La imprudencia en la acción ha de ser entendida en este marco. La imprudencia es la actitud de aceptar el ser tal cual es y no intentar imponerle una segunda naturaleza (con pocas posibilidades de darse $\mathrm{y}$ 
que nos columbraría al fracaso). En una palabra, "adaptarse a la ocasión". Así lo indica Gracián en el Oráculo Manual.

Adaptarse a la ocasión. Dirigir, pensar, todo debe ser oportuno. Hay que decidirse cuando se puede, pues la ocasión no espera a nadie. En la vida no hay que servirse de generalidades, a no ser por virtud. La voluntad no tiene leyes precisas: el agua que hoy se rechaza mañana se beberá (...). El sabio conoce bien dónde está el prudente norte: en adaptarse a la ocasión ${ }^{3}$

Ni que decir tiene que hemos dejado una cuestión abierta: ¿por qué es tan complicado alcanzar el deber ser? Porque la pasión es inherente al hombre y éste siempre ha de contar con ella? El deber ser tironea a un lado opuesto a la misma, pero no por ello fenece el esfuerzo de la pasión.

Comprendido esto, encontramos un medio para vencer la pasión, asumiendo su inmortalidad dentro del cuerpo humano: dejarla actuar pero evitar que domine. No podemos fusilar la pasión, no obstante, podemos controlar la respuesta que demos ante ella, es decir, podemos resemantizarla.

En este punto, establecía Ordóñez un caso de consulta. Una mujer de cuarenta años que se separa y decide que quiere desarrollarse, por vez primera en su vida vitalmente. Para ello, decide que se quiere dedicar a la pintura. El conflicto surge cuando se apercibe que tiene una hija y también desea "ser madre". Tenemos aquí un conflicto entre dos pasiones, que en este caso serían incompatibles. La solución no viene de la eliminación del ser, de las pasiones, porque como vimos eso es imposible. De hecho, el intento de eliminar una de las dos sólo produce sufrimiento (el generado por la pasión mutilada). Si cambiamos la dinámica del deber ser por el ser, el filósofo aplicado debería fomentar una resemantización que fomentase el ser, esto es, la integración de las dos pasiones y su aceptación en un nuevo marco significativo. Por ejemplo, como se propuso en la sala, que la madre enseñe a pintar a la hija.

El último tema fue apenas sugerido por Ordóñez: ¿en qué consiste el arte de elegir? Para Gracián, elegir significa "elegir el objeto bueno". Ese objeto bueno no conduce a un idealismo generalizador sino que se ha de

\footnotetext{
${ }^{3}$ GRACIÁN, B.: Oráculo Manual, 288, Temas de Hoy, Madrid 1993. Págs. 164-165. Edición de José Ignacio Díez Fernández.
} 
especificar para cada sujeto. Ahora bien, ese "objeto bueno", se pregunta Ordóñez, es lo que me satisface o lo prudente, es decir, lo que frena mi pasión. La enorme paradoja es que si la elección depende de la prudencia (de lo mejor y no de las pasiones) no seríamos nosotros quien eligiríamos sino que un ente (podríamos llamarlo lo más razonable) haría que todos eligiésemos lo mismo. En caso contrario, se apunta por una postura imprudente, pero, a la vez, sería la del ser, la de la pasión que nos constituye.

\section{El afrontamiento calderoniano de conflictos existenciales.}

La profesora de la Universidad Autónoma de Madrid, Juana SánchezGey, comenzó con una idea epictetea, que ha sido inspiración profesional del autor de la primera tesis doctoral sobre Filosofía Aplicada (Prof. Dr. Peter Raabe, Universidad Fraser Valley en Canadá): una filosofía que no alivia algún sufrimiento humano es vano. Sánchez-Gey nos ilustró con dos modos en que el pensamiento de Calderón de la Barca rinde utilidad a nuestra disciplina: (1) la obra calderoniana ofrece un marco en que se desarrolla un discurso significativo para el orientador filosófico y (2) provee de contenidos concretos de utilidad para el trabajo individual o grupal.

En cuanto al marco, se advierte que la filosofía española no ha de buscarse exclusivamente en los moldes encorsetados del sistema o el ensayo reflexivo: "No es el carácter sistemático, ni la abstracción lo que hace a la reflexión que sea filosófica, sino que el pensamiento sea riguroso, comunicable, y que aporte nuevo saber" ". Siguiendo una profunda tradición que hunde sus raíces en el Quijote de Cervantes, Sánchez-Gey demanda la raíz filosófica de nuestra literatura. Razón de ésta aseveración es la obra del autor de La vida es sueño. Tal afirmación no es gratuita sino que nuestra pensadora lo justifica afirmando que la literatura calderoniana, y por extensión la española, discute las cuestiones más hondas de la condición humana, como veremos más adelante. Aparte

\footnotetext{
${ }^{4}$ SÁNCHEZ-GEY VENEGAS, J.: "Sobre el hombre calderoniano o la razón de una duda" en AA.VV.: Calderón de la Barca desde la modernidad, Fundación Fernando Rielo, Madrid, 2001. Pág. 161.
} 
de los temas está el formato en que esas verdades se nos abren a nuestro mundo: son auténticas evidencias (en el sentido zambraniano) que provocan una detención de la lectura y de la vida puesto que necesitan reflexionarse.

Por otra parte, la filosofía española siempre es una "filosofía con apellidos". El pensador español ha avanzado sobre el sentido de la vida, de la libertad, de la conciencia, de la religión,.... En todo momento, ésta ha estado transida de una vitalidad respaldada por un sujeto que habla (se queja, agradece, grita, llora, ríe,...), una persona que actúa (se hace levantisco, fenece en tristeza, manifiesta locura o incomprensión,...) o una situación en que todos tienen derecho a manifestar su particularidad. La filosofía española no sólo ha versado sobre la vida sino que su misma entraña es ser viviente; por consiguiente, conforma una "filosofía con cintura", según el parecer de la profesora de la UAM. La vida requiere una flexibilidad que trasciende el sistema sin negarlo. No podía ser de otra forma: si pensamos en filósofos españoles contemporáneos advienen a nuestra mente especialistas en ética (Savater, Amelia Valcárcel, Victoria Camps,...) o que se han dedicado a ella con interés.

Resumiendo, el marco propicio para la filosofía aplicada que trae el pensamiento calderoniano implica: (1) acercarnos a la filosofía desde la literatura, (2) ubicarnos en las preguntas más hondas de la condición humana, (3) fraguar un saber de tipo evidencial, (4) ponernos en contacto con un pensamiento desde la vida y (5) conectarnos con inquietudes éticas. Concretemos algunos temas calderonianos.

El primero sería el análisis de la libertad humana. El ser humano es capaz de ser libre a pesar de las constricciones físicas. Según el ejemplo epicteteo, se podrá encadenar la pierna de un esclavo, pero su espíritu sólo será siervo por opción personal. La razón determina la libertad del individuo. Además, las virtudes intelectuales y éticas tradicionales como la prudencia o la templanza protegen tal derecho y deber. Decimos bien, deber, porque el filósofo no sólo tiene el derecho de ser libre, su misma esencia debería ser la constitución de su ser como ser libre. Segismundo, el protagonista de La vida es sueño, es semblante de ese anhelo.

Adherimos lo anterior a la pronunciada por los filósofos helenos o por el contemporáneo Pierre Hadot: ser filósofo es más que conocer un conjunto de teorías filosóficas, la filosofía es un modo específico de vivir. 
Por eso, la condición de filósofo no se gana desde el hecho de aprobar medio centenar de exámenes, sino que se obtiene desde la mirada escrutadora de los demás. Un ejemplo de filósofo español que respeta este sentido fue Sanz del Río, introductor del krausismo en nuestro país.

El segundo es la búsqueda de la unidad y la armonía. Lejos de pretender una exclusión del otro, la unidad calderoniana aúna la naturaleza esquizoide y anima al sujeto a encontrar su centro y desde ahí andar el propio camino.

Tema nodal, es la propuesta de Sánchez-Gey referente al amor: quien quiera entender qué es el amor, sólo ha de leer La vida es sueño. Allí, se destaca un auténtico proceso de amor. No asistimos a un sentimiento de dependencia o de falsedad cortés sino a un proceso análogo al leibniciano (amar es encontrar la felicidad propia en la del otro) o al descubrimiento del yo desde el tú.

Precisamente, el punto anterior nos conduce a otro asunto calderoniano: la conciencia y la identidad. Toda identidad es dialógica e integradora. No hay yo sin tú. No hay identidad sin una mirada que rescate abismos personales que, nosotros mismos, desconocemos. Obviamente, esto posee connotaciones éticas de indudable valor. No haría falta justificar la moral o la ética de modo deontológico, sino que una mera postura pragmática sería suficiente: preocúpate del otro, aunque sea por tu propio interés 5

Por último, repetir que no se hace apología de todo esto desde contundentes argumentos sino desde ese tipismo de la reflexión española que hace manar sus razones desde la misma vida actuante dentro de la narración.

\section{Blas Zambrano, compromiso educativo y social}

Nos sumamos a la afirmación que hiciera el profesor José Luís Mora en su conferencia: "Blas Zambrano no sólo debe ser estudiado como padre

\footnotetext{
${ }^{5}$ Ésta es una de las conclusiones del planteamiento del profesor Ramón Queraltó: la ética no sólo interesa individualmente sino que a las mismas empresas. El desarrollo de la ética empresarial fomentar el buen clima entre los que la componen y, por ende, aumenta la productividad (Cfr. Ética, tecnología y valores en la sociedad global. El caballo de Troya al revés. Tecnos, Madrid, 2003).
} 
de María Zambrano sino «como él mismo» porque posee valores que le son propios".

Sin duda alguna, María Zambrano estaba equivocada cuando aseveraba que su padre había publicado pocos escritos. La labor de búsqueda y compilación de nuestro conferenciante en el libro Artículos, relatos y otros escritos de Blas Zambrano, da cuenta de ello.

Blas Zambrano nace en Segura de León, en Extremadura, en 1874. Procede de una familia de propietarios venidos a menos, lo cual le condujo a una experiencia dual que combinaba su ascendencia burguesa y el contacto con el proletariado. Esto será patente en toda su obra, pues busca el ascenso social del obrero a través de la cultura. Esta mezcla será también patente en los libros de su hija María. Así lo cuenta José Luís Mora.

En el nacimiento mismo estaba ya el fuerte contraste entre los ideales del tiempo pasado de propiedades rurales, la "Arqueópolis de encinas milenarias" y sueños de reformas religiosas, de "catolicismo muy cristiano", y los nuevos tiempos de mudanzas y transformaciones. Es difícil entender a don Blas y a los Zambrano, incluida la propia hija, sin la referencia a estos orígenes donde se vivían, al tiempo, las glorias recordadas y las tragedias sufridas ${ }^{6}$

Las fases de su vida son siete, de las que glosó cinco el profesor Mora.

La primera, la vivida en Alájar, ofreció a Zambrano la posibilidad de conectar con el anarquismo y con líneas religiosas heterodoxas a través de su padre Diego Zambrano. Precisamente, la enfermedad de éste último impidió que el joven Blas estudiase Filosofía, quedando sólo en Magisterio. Quien sí la estudió fue su hermano, que recalaría en una farmacia granadina, cuyas puertas permanecen abiertas casi un siglo después con el rótulo "Farmacia Zambrano". Su periodo en Sevilla le permite contactar con intelectuales relacionados con la Institución Libre de Enseñanza, los ideales krausistas como Simon Fons, Urbano González Serrano, Pedro Alcántara, Manuel Sales y Ferré o Federico de Castro. El impacto de la ciudad en su vida se ve reflejado en uno de sus relatos, donde sitúa a una de sus protagonistas entrando por la ancha calle Castilla, traspasando la calle San Jorge o llegando a la Plaza Nueva.

\footnotetext{
${ }^{6}$ MORA GARCÍA, J.L.: "Blas J. Zambrano", Ateneistas ilustres II, Madrid, Ateneo de Madrid, 2007. Pág.742.
} 
La tercera fase de su vida, la de Granada, fue una de las más intensas. Culminada su formación se lanza a la generación de La obra, institución de carácter socialista (aunque no política) en que se escanció el ideal zambraniano de la educación como medio de desarrollo del obrero. Cuenta Mora que allí se formaba a obreros con escasa formación y no sólo en temas de escasa complejidad, sino que contaron con personalidades y conferenciantes que llenaron salas con más de mil personas. La obra contará con libros e instrumentos pedagógicos de los que hacían uso personas de todos los niveles sociales. Aventura Mora que tal anhelo fuera por un espíritu, hoy perdido, en el que la construcción personal del individuo era uno de los débitos esenciales hacia uno mismo.

Será también aquel el lugar del nacimiento del periódico $X$. Éste desarrollaba los ideales liberadores (no liberales) zambranianos y llegó a ser motivo de conflicto con otros de los periódicos granadinos: El triunfo. Las disquisiciones llegaron a encontrar fricción con el alto clero, al punto de acusar a Blas Zambrano de anticristo. Mora se pregunta por las razones de la violenta respuesta a los escritos de Zambrano, puesto que éstos no perseguían el combate a campo abierto. De hecho, son conocidos algunos de sus artículos que se negaban a la idea de la lucha abogando más por la solidaridad.

La cuarta etapa se inscribe en Vélez-Málaga, lugar de nacimiento de María Zambrano. No estuvo allí mucho tiempo, aunque es recordado como un buen maestro. Esto lo confirman los diversos premios y reconocimientos que recibe: "hasta estuvo propuesto para la obtención de la cruz de Alfonso XII que finalmente no le fue concedida por no llevar quince años de servicios" ${ }^{\text {. }}$. De aquella época data un escrito donde recomienda la educación moral del alumnado. Para ello, no es suficiente con transmitir contenidos sino responsabilizarse con el alumno y hacerlo consciente del interés del maestro por su discípulo, que sepa que se apena cuando el discípulo no se comporta de modo adecuado.

La cuarta etapa será la de Segovia. Él intentó hacer ciudad, es decir, fomentar el encuentro entre los segovianos usando como medio, nuevamente, la cultura. Será el periodo de la Universidad Popular Segoviana, de la tertulia con Antonio Machado, de sus publicaciones en

\footnotetext{
${ }^{7}$ Ibidem. Pág. 755.
} 
Castilla y de su desafección política por las injusticias caciquiles que veía.

Por último, Madrid es su época final. Colmataría allí lo que había hecho toda su vida. Imparte conferencias y clases, pero su actividad se va amenguando progresivamente ${ }^{8}$.

Uno de los temas esenciales en Zambrano son las ideas de la alteridad y de la españolidad. Para el maestro de Extremadura, el sujeto sólo se constituye desde la mirada del otro, de ahí su necesidad de compromiso con lo demás, de lo cual dejaría huella en Granada y en Segovia. En este sentido, era importante "hacer ciudad" y hacer estado. La integración del otro no respondería sólo a un altruismo desprovisto de beneficio personal sino que implicaba una demanda que surgía de la propia creación de la identidad como sujeto social o de la creación de la dimensión social del sujeto.

Asimismo, Zambrano se inscribe en el modelo de personas para los que las palabras y el ser deben coincidir, de ahí su coherencia a lo largo de toda su vida. Por tanto, su vida era reflejo de sus obras y viceversa. Los discursos encendidos o apasionados no se circunscriben a un mero colorido de retórica artificial sino a una vivencia comprometida con el mundo que le rodeaba.

Esto último le conduce al concepto de "razón unitaria", que se corresponde con la "razón poética" de su hija. Don Blas comprende que más allá de la reducción moderna de la racionalidad hay un concepto que trasciende sus fronteras y permite alzarse a conocimientos latentes, palpitantes y vitales. Razón de ello será que camine por distintos géneros literarios: ensayo, diálogo filosófico y novela. Razón unitaria que descansa en una razón compasiva (y profundamente española) tal y como recogemos de un articulo suyo en que se queja de las imposiciones a Alemania durante la I Guerra Mundial.

Si el español representa algo en el mundo, es su viril rendimiento a la razón práctica, su idolatría de la diosa Temis, a quien, si alguna vez vuelve la espalda, es para ponerse de parte del caído, así sea un galeote ${ }^{9}$

\footnotetext{
${ }^{8}$ Cfr. MORA, J.L.: "Introducción” en ZAMBRANO, B.: Artículos, relatos y otros escritos, Diputación provincial de Badajoz, Badajoz, 1998. Pág. 19.

${ }^{9}$ ZAMBRANO, B.: Artículos, relatos... Págs. 235-236.
} 


\section{García Morente en la fundamentación de la Filosofía Aplicada}

Manuel García Morente sería el autor que el profesor de la Universidad Pablo de Olavide Jesús López Baroni nos puso en relación con la Filosofía Aplicada. García Morente es conocido por ser uno de los traductores contemporáneos de gran cantidad de textos de la modernidad filosófica. De hecho, introduce a Kant en España, pero también a Kant o Russell e incluso intentó la creación de una estructura semejante a la Institución de Libre Enseñanza para niveles preuniversitarios.

Según refiere López Baroni, García Morente despuntó desde muy joven: "A los veinticinco años, catedrático de la Universidad de Madrid. ¡El catedrático más joven de España!"10. De su vida, destaca el giro que le hizo pasar de intenso conocedor y practicante del republicanismo a sacerdote y crítico profundo con los que, previamente, se había alineado.

¿Qué encontramos en García Morente de utilidad para la Filosofía Aplicada? Una fundamentación y un modo de investigar dentro de la consulta. García Morente se plantea una superación del positivismo cuando se intenta investigar al hombre. Siendo conscientes de la diferencia diltheyana de las ciencias de la naturaleza y del espíritu, el filósofo jienense se acerca a la intrahistoria unamuniana. La historia de cada persona es distinta por lo que no se pueden establecer reglas fijas para su indagación.

El objeto de la historia no es genérico, sino individual. No establece la historia leyes de un género o de una especie que determinen un acontecer fijo, constante, igual a sí mismo, siempre que aparece la misma esencia. No; sino que la historia es la determinación de hechos particulares en un lugar y en un tiempo concreto. Por consiguiente, la historia en ese sentido no puede ser ciencia; tiene que ser pura narración, no conocimiento científico ${ }^{11}$

El historicismo morentino es análogo al orteguiano. Con el autor de la razón vital, compartiría más que clases en Madrid. Sus ideas son coincidentes en muchos puntos y jamás se alejó de él. Muestra de ello, es la comparación del siguiente texto con el faciendum del pensador madrileño.

\footnotetext{
${ }^{10}$ GARCÍA MORENTE, M.: Diario de los ejercicios espirituales, en Obras completas I. Pág. 542.

${ }^{11}$ GARCÍA MORENTE, M.: La estructura de la historia, en Obras completas II, 1942. Pág. 241.
} 
La vida es precisamente esa anticipación, ese afán de querer ser (...). La vida, pues, es una carrera; la vida es algo que corre en busca de sí mismo; la vida camina en busca de la vida y el rastro que deja tras de sí después de haber caminado, es ya materia inerte ${ }^{12}$

No obstante, denuncia Baroni, en ocasiones, llegó a hacer una hermenéutica de Ortega poco fiel a sus textos.

Para Morente, el filósofo no es un agente de la explicación sino de la comprensión. Eso es nodal en la consulta filosófica. El filósofo ha de desarrollar sus capacidades de simpatía (sym-pathos) y empatía para entender lo que está frente a él. Sólo con ellas, es posible internarse en "la vida privada", aquella que es "radical, esencialmente la e cada hombre, la de cada individuo, la de cada persona"13.

\section{María Zambrano: asunción y trascendencia de la razón moderna en la Filosofía Aplicada.}

José Barrientos, que realizó una tesis doctoral sobre las imbricaciones del pensamiento de María Zambrano y la filosofía aplicada en 2009, nos abrió su sistema sobre el particular.

En un primer paso, rastrea cómo María Zambrano expone una profunda raigambre familiar educativa ${ }^{14}$. Tanto sus padres como abuelo paterno fueron maestros comprometidos. Sus ideas de la filosofía se alinea dentro del planteamiento de la filosofía para niños (práctica filosófica no ajena a la filosofía aplicada): la educación supone ayudar a pensar a los niños.

Respecto a las vinculaciones con la Filosofía Aplicada, refiere Barrientos que, según Juan Carlos Marset, ella estudió filosofía "para salvar a su padre". Blas Zambrano sufría frecuentes crisis existenciales durante la adolescencia de su hija, que, incluso, le llevarían a pensar en el

\footnotetext{
${ }^{12}$ GARCÍA MORENTE, M.: Lecciones preliminares de filosofía. Ontología de la vida, en Obras completas II, 1942. Págs. 309-310.

${ }^{13}$ GARCÍA MORENTE, M.: Ensayo sobre la vida privada, en Obras completas II, 1935. Pág. 426.

${ }^{14}$ Ella misma se interesó por la educación: impartió clases con su madre, trabajó para las Misiones Populares, etc...
} 
suicidio. Comprendió que si la filosofía suponía un desciframiento, éste podría ser la terapéutica que necesitaba su padre.

Esta dificultad expresiva del padre coincide en parte con la definición que María Zambrano dio de la filosofía años después: "Pensar es descifrar lo que se siente". Fue precisamente en aquellos años cuando María Zambrano decidió estudiar filosofía "para salvar" a su padre ${ }^{15}$

La filosofía serviría a Zambrano para enfrentar otros motivos de consternación existencial: la muerte de su madre, el exilio, el fusilamiento de Manuel Muñoz (esposo de su hermana), la muerte de su hermana, la de amigos como Lezama Lima, etc... Sin embargo, también fue de utilidad para los que la rodeaban. Como muestra dos textos y un caso paradigmático.

El primero pertenece al epistolario entre nuestra pensadora y la viuda de Lezama Lima y manifiesta la ayuda que supone a María Luisa Bautista leer las cartas de Zambrano.

Ud. no es capaz de imaginarse, mi querida María, lo que Ud. me acompaña con sus cartas, Ud., tan solita, y cómo siento su compañía cada vez que las recibo y ver qué bien se sabe la pena cuando me dice en palabras hermosísimas: "sé de ese cuchillo, de ese hielo, de esas brasas, de esa desolación, de ese vacío y de ese dirigirse a él por un instante como si estuviera a su lado"16

La segunda procede de la correspondencia entre Zambrano y Emilio Prados.

Sí -lo siento- que este trabajo me va a ayudar mucho para lo que hago y para mi vida. Lo espero con enormes deseos. Y escríbeme. No me dejes. Sé que te acuerdas de mí, lo siento; pero, necesito tu palabra tierna ${ }^{17}$

Por último, una carta de 1974 dirigida a Agustín Andreu narra un caso, de modo escueto (quince líneas), enjundioso para nuestro argumento.

\footnotetext{
${ }^{15}$ MARSET, J.C.: María Zambrano. I. Los años de formación, Fundación José Manuel Lara, Sevilla, 2004. Pág. 257.

${ }^{16}$ LEZAMA LIMA, J. - ZAMBRANO ALARCÓN, M. - BAUTISTA, M.L.: Correspondencia, Espuela de Plata, Madrid, 2006. Pág. 231.

${ }^{17}$ C 26/2/1959. Pág. 2. Cursivas nuestras.
} 
María conoció en Roma a una joven filósofa "que tenía el pelo como Simone y Safo -pequeña, morena-" ${ }^{\prime 1}$. La joven decide suicidarse porque nunca escuchó la palabra amor. Se sentía fea y creyó que ésta era razón suficiente para nunca experimentar ese sentimiento que anhelaba. Había un joven fraile enamorado de ella, pero tal era su pena que la adolescente nunca se percató de ello. El suicidio es llevado a la práctica y esto postra a su hermano. Por entonces, éste había decidido casarse y ante la muerte de ella, se siente culpable por no haberle dedicado el cariño suficiente. No puede soportarlo e intentar repetir la acción de su hermana. María decía actuar: "Y para que no hiciera lo mismo lo tuvimos en casa dos meses".

¿En qué sentido proporciona María Zambrano un molde para el actuar del filósofo aplicado? Ante todo, define el filosofar como un camino en el que se superan obstáculos que detienen el proceso de profundización vital. La tarea filosófica se asemeja al acto de constitución de la identidad: filosofar es descifrar el sentimiento originario y esto se vincular, sin duda, con la construcción de lo que auténticamente somos.

Los momentos de crisis, aquellos en los que el consultante acaba en el gabinete filosófico, se corresponden con oportunidades para que el filósofo aplicado zambraniano actúe. Esa actuación se cifra en una clarificación de la situación que impide el tránsito o que crea una estenosis que hace peligrar el normal flujo de los días y las horas. Ejemplo de ello es el delirio, en el cual el sujeto repite una y otra vez el pasado y se muestra incapaz de inteligir el futuro. La "terapeútica" zambraniana conlleva dar un espacio y un tiempo al contenido del delirio, puesto que éste depende de la imposibilidad del sujeto para darle (en tiempos pretéritos) las condiciones necesarias para su desarrollo.

Zambrano posibilita el estudio del significado de la desorientación y del descentramiento. Asimismo, abre vías para a comprensión de una trascendencia que fomente el progreso vital. Barrientos se entretuvo en algunos temas más: la necesidad de que el tiempo de la vida no acate la sucesividad sino que sea significativo y troque en el tiempo de la persona, la perentoriedad de usar la evidencia para el conocimiento junto a la razón argumental, el proceso de abismamiento y renacer como

\footnotetext{
${ }^{18}$ ZAMBRANO ALARCÓN, M. - ANDREU, A.: Cartas de la Pièce (correspondencia con Agustín Andreu), Pretextos-Universidad Politécnica de Valencia, Valencia, 2002. Pág. 129.
} 
modelo en el proceso filosófico, etc... Vertebrando todo ello, encontraba una idea basal: el pensamiento zambraniano es un revulsivo a la razón moderna lógico-argumental, al devolver al cartesianismo y el hegelianismo una razón que excede sus límites sin negar la anterior. Las dimensiones poéticas o narrativas de la epistemología alzan su voz, sin intento de absolutizarse sobre las otras. Propuesta similar podría hacerse para la teoría clásica de la filosofía aplicada. Una razón poética para la filosofía aplicada pretende sacar la posibilidad de una razón vital actuante de las cárceles impuestas por un racionalismo galopante. Si la Filosofía Aplicada no sólo trata con la vida sino que es vida en acción, la razón más oportuna para ésta habría de estar transida por una razónpoética. Ésta, además de no negar el tejido lógico-argumental, fragua un contacto con la vida que la modernidad creyó de segundo nivel y ante la cual llegó a ruborizarse. Barrientos señalará que sin esa devolución a la filosofía aplicada, muchos casos del gabinete filosófico quedarán sin respuesta puesto que pensar (lógico-argumental) y ser-hacer (vitalidad) no encontrarán concierto, eternizándose el "sé lo que tengo que hacer pero no consigo llevarlo a buen puerto".

\section{Julián Marías: sistematismo, concreción, horizonte y comprensión para la Filosofía Aplicada}

Jorge Dias, primer presidente de la Associaçao Portuguesa para o Aconselhamento Ético, abordó algunas ideas del pensamiento de Julián Marías desde la nuestra óptica particular. Partir de la primera frase de Razón de la filosofía, habría de ser suficiente para justificar el nexo entre la reflexión de Marías y la Filosofía Aplicada.

Ante todo, el filósofo practica el pensamiento en una situación concreta, glosará Dias. La mayor especificación de la filosofía se obtiene desde la palabra del consultante. Esa concreción se obtiene en varios puntos dentro de la obra del discípulo de Ortega, aunque la más interesante para Dias es la de felicidad. Según Dias, una de las mayores divergencias entre Ortega y Gasset y Julián Marías es que el segundo 
precisa nociones en apenas insinuadas por el primero. Un ejemplo se cifra en el referido concepto de "felicidad"19

Otro elemento útil para la filosofía aplicada es el estudio de la noción "necesidad", pues todo filosofar parte de una necesidad vital ${ }^{20}$. Conocer la caracterización de la "necesidad" y sus constituyentes dotará al consultante de un instrumento para su trabajo de consulta.

En Introducción a la filosofía se detiene el discípulo orteguiano en otras categorías de uso en el gabinete filosófico. Añade a la noción de necesidad, la separación entre creencias e ideas ${ }^{21}$.

Dias se sirve del sistematismo de Julián Marías para animar a los orientadores filosóficos a que hagan un tratamiento de semejante índole de la vida. El uso de mapas de pensamiento sistemáticos se imbuyen de éste espíritu ordenador y clarificador. No hay consulta filosófica, sin ese orden previo a que ayuda el orientador.

El orden conduce a una jerarquización en que despuntan una serie de asuntos sobre otros. El horizonte de problemas contribuirá a iluminar el conflicto del consultante. En esto no se hace sino seguir una metodología propia del filósofo madrileño.

El círculo creado entre vida y pensamiento no ha de pasarse por alto en la consulta. La reflexión y la vida, al igual que en la obra mariana, deben imbricarse: el análisis de la vida ha de ir seguido por el del pensamiento y el de éste por la vida y vuelta a comenzar.

El método agregará a los puntos anteriores el hecho de estar atravesado por la fenomenología: primero se describirá lo que está sucediendo. La descripción ha de saberse distinguir de la explicación y de la comprensión, siendo estas dos últimas resultado de la primera acción.

La funcionalidad y la finalidad serán también motivos de meditación en Marías. Aquí podemos añadir la pregunta por el sentido existencial o por el proyecto vital, que es tan querido en el método Proyect del filósofo portugués.

\footnotetext{
${ }^{19}$ A pesar de que en este término aquí hay una mayor prolijidad escriturística de Marías sobre Ortega, pocos ejemplos más se pueden dar para defender la conclusión de Dias. Al menos esa es nuestra postura.

${ }^{20}$ Aquí, Marías vuelve a beber de Ortega: recuérdese su idea de la vida como que-hacer.

${ }^{21}$ Obsta decir que las ideas y las creencias componen la primera parte de una obra homónima de Ortega y Gasset.
} 
Marías tiene una clara conciencia entre lo cuantitativo y lo cualitativo. Dias advierte que esto ha de trasladarse a la consulta: saber qué se ha de traducir en número y qué, no.

Por último, el diálogo es el eje de la consulta. Sin él, no es posible esclarecer los ingredientes básicos del problema ni hacer el contraste que conduzca a su resolución.

En suma, Dias nos aconsejaba investigar las siguientes ideas de Julián Marías para aplicarlas a la profesión que aquí nos incumbe: concreción, necesidad, felicidad, creencias e ideas, sistema y orden, pensamiento y vida, horizonte o marco global, descripción frente a explicación y comprensión, funcionalidad y finalidad, cuantitativo y cualitativo, y el diálogo.

\section{Bibliografía}

BARRIENTOS RASTROJO, J.: Introducción al asesoramiento y la orientación filosófica, Ideapress, Tenerife, 2005.

- "Del pensar zambranista a la filosofía poiética en la consulta filosófica" en Philosophers as Philosophical Counselors, X-XI, Sevilla, 2006. Págs. 207-221.

GRACIÁN, B.: Oráculo Manua, Temas de Hoy, Madrid 1993.

LEZAMA LIMA, J. - ZAMBRANO ALARCÓN, M. - BAUTISTA, M.L.: Correspondencia, Espuela de Plata, Madrid, 2006.

MARSET, J.C.: María Zambrano. I. Los años de formación, Fundación José Manuel Lara, Sevilla, 2004.

MORA GARCÍA, J.L.: MORA GARCÍA, J.L.: "Blas J. Zambrano", Ateneistas ilustres II, Madrid, Ateneo de Madrid, 2007.

- "Introducción" en ZAMBRANO, B.: Artículos, relatos y otros escritos, Diputación provincial de Badajoz, Badajoz, 1998. Págs. 3-32.

SÁNCHEZ-GEY VENEGAS, J.: "Sobre el hombre calderoniano o la razón de una duda" en AA.VV.: Calderón de la Barca desde la modernidad, Fundación Fernando Rielo, Madrid, 2001. Págs. 159-172.

ZAMBRANO, B.: Artículos, relatos y otros escritos, Diputación provincial de Badajoz, Badajoz, 1998 
ZAMBRANO ALARCÓN, M. - ANDREU, A.: Cartas de la Pièce (correspondencia con Agustín Andreu), Pretextos-Universidad Politécnica de Valencia, Valencia, 2002. 